Annales Geophysicae (2002) 20: 487-499 (c) European Geophysical Society 2002

\title{
HF radar polar patch formation revisited: summer and winter variations in dayside plasma structuring
}

\author{
S. E. Milan, M. Lester, and T. K. Yeoman \\ Department of Physics and Astronomy, Leicester University, Leicester LE1 7RH, UK
}

Received: 10 May 2001 - Revised: 5 November 2001 - Accepted: 20 November 2001

\begin{abstract}
Three intervals of polar patch formation, as observed by the CUTLASS Finland HF coherent radar, are presented. Simultaneous observations from a vertical ionosonde located at Longyearbyen on Svalbard, situated in the dayside convection throat region, allow for F-region plasma structuring, leading to polar cap patch formation to be determined. Solar wind and interplanetary magnetic field (IMF) pre-cursors of polar patch formation are investigated with MFI and SWE measurements from the Wind spacecraft. We find that in the cases studied polar cap patches are formed in response to changes in the orientation of the IMF, especially in the $B_{Y}$ component. The resultant changes in the dayside convection pattern alter the source of plasma drifting through the convection throat region into the polar cap. When the convection flow is directed predominantly polewards, high density sub-auroral or mid-latitude plasma enters the polar cap; when flow is directed zonally, low density plasma entrained in the convection return flow replaces it. This mechanism can act to significantly structure the plasma density at sub-auroral or mid-latitudes as well as in the polar cap. In winter months, polar patches appear to be produced by depletions in an otherwise high plasma density tongue of ionisation. In summer months, patches are enhancements of an otherwise low density tongue of ionisation.
\end{abstract}

Key words. Ionosphere (ionospheric irregularities; plasma convection; polar ionosphere)

\section{Introduction}

Polar patches are regions of F-region electron density enhanced above a lower background level which propagate in the antisunward convection flow across the polar cap from a source near the cusp region towards the nightside auroral zone (Buchau et al., 1983; Weber et al., 1984; see also the review by Crowley, 1996). Due to the long lifetime of plasma at F-region altitudes, these patches can retain their

Correspondence to: S. E. Milan (Steve.Milan@ion.le.ac.uk) elevated electron density for several hours, even when they enter regions of low solar production, such as the nightside ionosphere. That a "tongue of ionisation" should be drawn from sunlit mid-latitudes, through the cusp region, and into the polar cap is relatively well established (Knudsen, 1974). However, controversy still surrounds the contribution to the plasma enhancement from soft precipitation in the cusp region (for instance, most recently, Walker et al., 1999), and the means by which the plasma becomes structured into "patches" or "blobs" as opposed to a uniform "tongue". Three rival mechanisms by which this structuring could arise are exemplified by the following studies. Based on modelling work, Anderson et al. (1988), Sojka et al. (1993), and Decker et al. (1994) demonstrated that patches could be formed through changes in the convection pattern, under the influence of variations in the interplanetary magnetic field (IMF), especially in the $B_{Y}$ component. Lockwood and Carlson (1992) suggested that a time-varying reconnection rate, or the transient occurrence of flux transfer events (FTEs), could act as a structuring mechanism. Lastly, it has been suggested that the electron density depletion between patches could arise from rapid plasma drift in short-lived east-west flow channels located in or near the cusp region, producing enhanced ion-frictional or Joule heating and hence an enhanced plasma recombination rate (Valladares et al., 1994; Rodger et al., 1994). These flow channels would be produced by FTEs, and hence this mechanism is also associated with transient reconnection. The present study investigates three intervals during which polar patch formation was observed by an HF coherent radar, the Finland station of the CUTLASS system. HF radars are becoming increasingly employed for the study of polar patches, and the reader is directed to several recent studies, including Rodger et al. (1994), Ogawa et al. (1998), Rodger and Graham (1996), and Rodger and Rosenberg (1999), for a discussion of the correlation between radar backscatter and polar patches. The Finland radar field-of-view overlooks a vertical ionosonde located at Longyearbyen on Svalbard. At local noon this ionosonde is generally located directly un- 

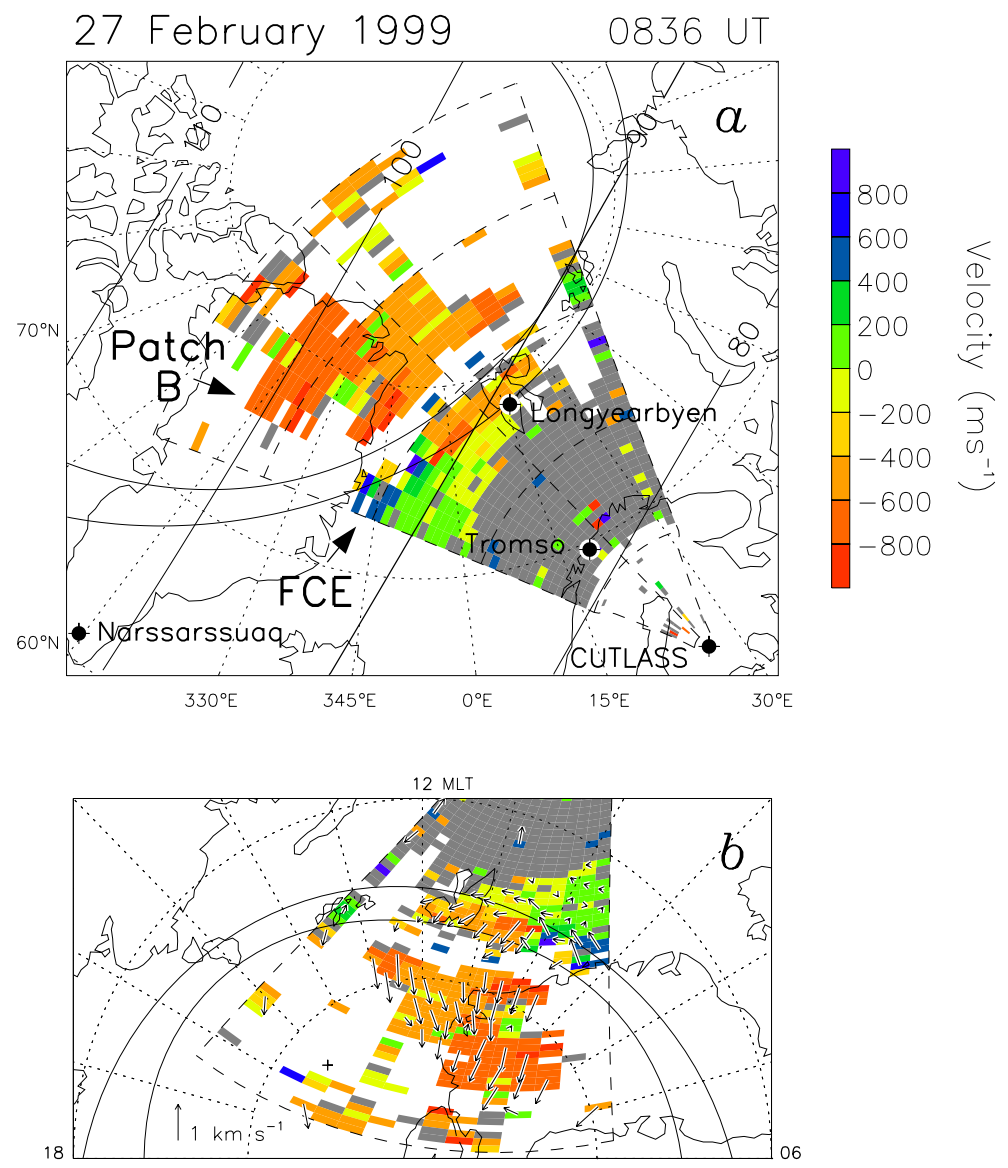

Fig. 1. The location of the field-ofview of the CUTLASS Finland radar system. Also indicated are the locations of the Longyearbyen, Troms $\varnothing$, and Narssarssuaq vertical ionosondes employed in the study. Line-of-sight plasma drift velocities from the radar scan starting 08:36 UT, on 27 February 1999, are presented. The statistical oval and solar zenith angles for this time are superimposed. The lower panel shows the same radar scan presented in a magnetic latitude and magnetic local time format. Beam-swung vectors are superimposed. der the auroral oval and cusp region, and hence is ideally situated for studying patch formation in situ. Supporting observations are provided by two ionosondes located at lower latitudes, at Narssarssuaq on Greenland and Troms $\varnothing$ in Norway. In addition, the solar wind and IMF conditions that give rise to polar patch formation are determined by measurements made by the Wind spacecraft. The first interval studied, during winter-spring conditions, is found to be remarkably similar to that investigated by Rodger et al. (1994), indicating the reproducibility of this polar patch formation scenario. However, some question is raised as to the exact plasma structuring mechanism at work. The second two examples come from summer and summer-autumn conditions, and again show a consistent mechanism for polar patch formation. We conclude that plasma structuring due to changes in the convection pattern under the influence of the IMF is the dominant mechanism at work in these examples.

\section{Observations and discussion}

The main instrument employed in this study is the CUTLASS Finland coherent HF radar, the field-of-view of which is illustrated in Fig. 1a. The radar scans through 16 beams (numbered clockwise from 0 to 15 ), producing a $52^{\circ}$ azimuth scan every $2 \mathrm{~min}$. Each beam is gated into 75 range cells,
$45 \mathrm{~km}$ in length, within which Doppler velocity (the lineof-sight component of the plasma drift velocity), backscatter power, and spectral width are resolved when backscatter with sufficient signal-to-noise ratio is observed. The reader is directed to Milan et al. (1997b) for a fuller description of the system. In the examples shown in this study, the radar was operating at a frequency of $12 \mathrm{MHz}$. As discussed by Milan et al. (1998), the condition necessary for observation of significant backscatter in a particular radar cell is a convolution of two factors: the presence of ionospheric irregularities at that point and favourable propagation conditions which allow the radar beam to illuminate the ionosphere at that point. In the examples shown, propagation does not appear to be a limiting factor, and backscatter can be observed throughout the field-of-view when irregularities are present.

\subsection{Interval 1}

The first interval studied is on 27 February 1999, between 06:00 and 10:00 UT, when the radar was located near local noon. In Fig. 1a, the Doppler velocity measured during the scan starting at 08:36 UT is illustrated. In Fig. 1b, this same scan is presented in a magnetic latitude and local time format, as will all subsequent spatial maps of backscatter. We will return to the interpretation of these observations later on, but for the present suffice it to say that positive (negative) ve- 


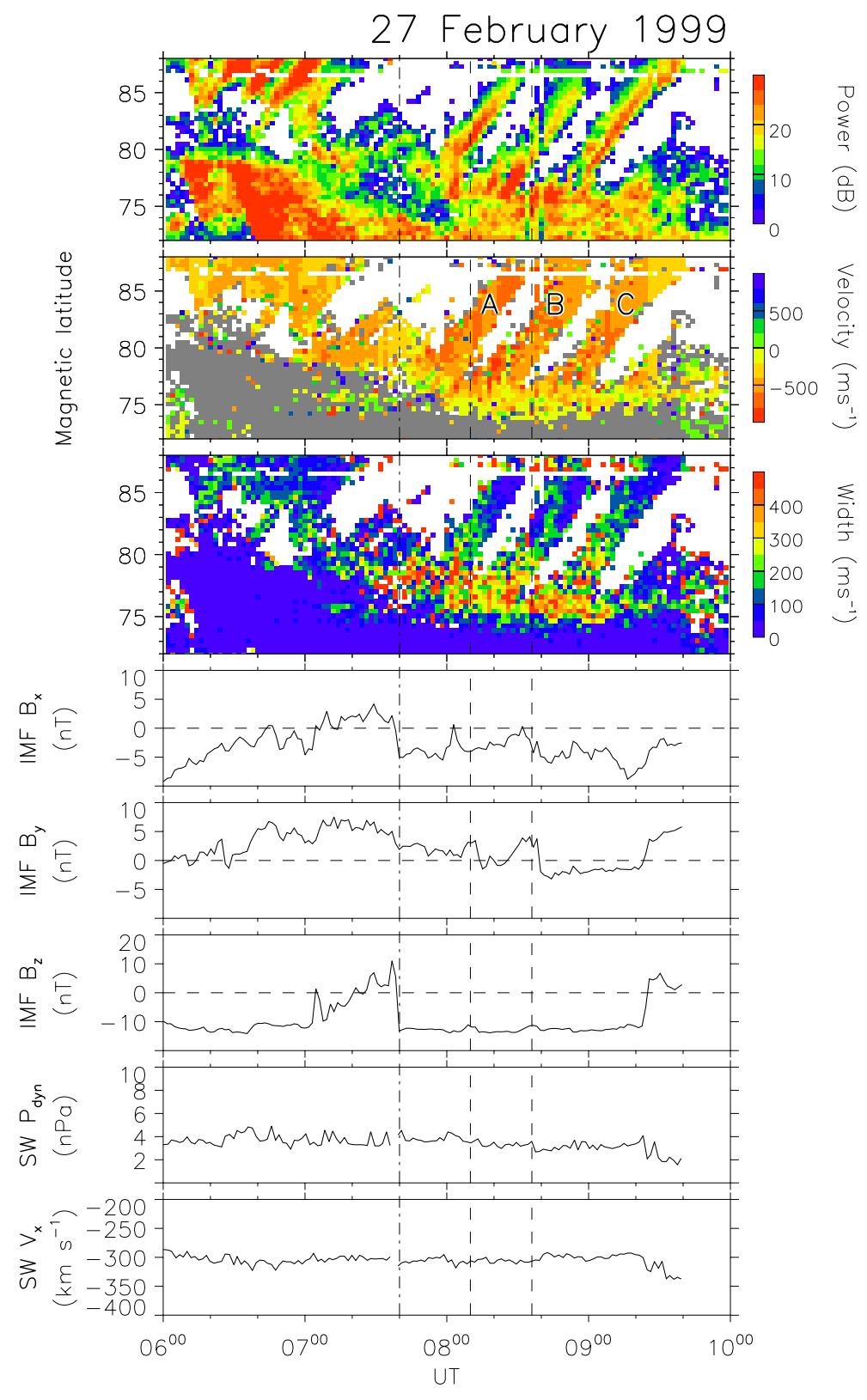

Fig. 2. The top three panels present latitude-time plots of backscatter power, line-of-sight plasma drift, and spectral width as measured by the radar. Three polar patches are indicated by the letters $\mathrm{A}, \mathrm{B}$, and $\mathrm{C}$. The bottom five panels present the $B_{X}, B_{Y}$, and $B_{Z}$ components of the IMF, and solar wind dynamic pressure and velocity, time-shifted for the expected solar wind propagation delay between the Wind spacecraft and the arrival of these features at the subsolar magnetopause.

locities represent plasma drift towards (away from) the radar along the line-of-sight. At the near ranges, the region of backscatter indicated in grey corresponds to ground clutter, identified by near-zero velocity and low spectral width (see Milan et al., 1997b). Superimposed on Fig. 1b are flow vectors determined by a beam-swinging technique, as described by Ruohoniemi et al. (1989). These vectors indicate that at lower magnetic latitudes, $75^{\circ}-77^{\circ}$, the flow has a significant eastward component. Polewards of this, the flow has rotated to point antisunwards. These flows will be described in more detail below.

The time evolution of the backscatter is shown in the top three panels of Fig. 2, which illustrate the backscatter power, line-of-sight velocity, and spectral width from beam 6 , presented in a latitude-time format. Throughout the in- terval ground clutter is observed at low ranges. Poleward of this, between 07:00 and 09:40 UT, is a $2^{\circ}-3^{\circ}$ wide, continuous region of ionospheric backscatter. Several previous authors have demonstrated that backscatter of this nature is usually co-located with the optical auroral oval, as observed from ground-based imagers (Rodger et al., 1995; Milan et al., 1999a, 1999b) or satellite-bourne imagers (Milan et al., 2000). Following this lead, we identify this region of backscatter as the dayside auroral oval. This interpretation is lent credence in Fig. 1, where this region of backscatter, just poleward of the ground clutter, is found to be closely co-located with the statistical auroral oval. Between 07:40 and 09:10 UT the spectral width of this backscatter is of the order of $300 \mathrm{~m} \mathrm{~s}^{-1}$ and above, a signature of the ionospheric footprint of the cusp region (Baker et al., 1990, 1995). 


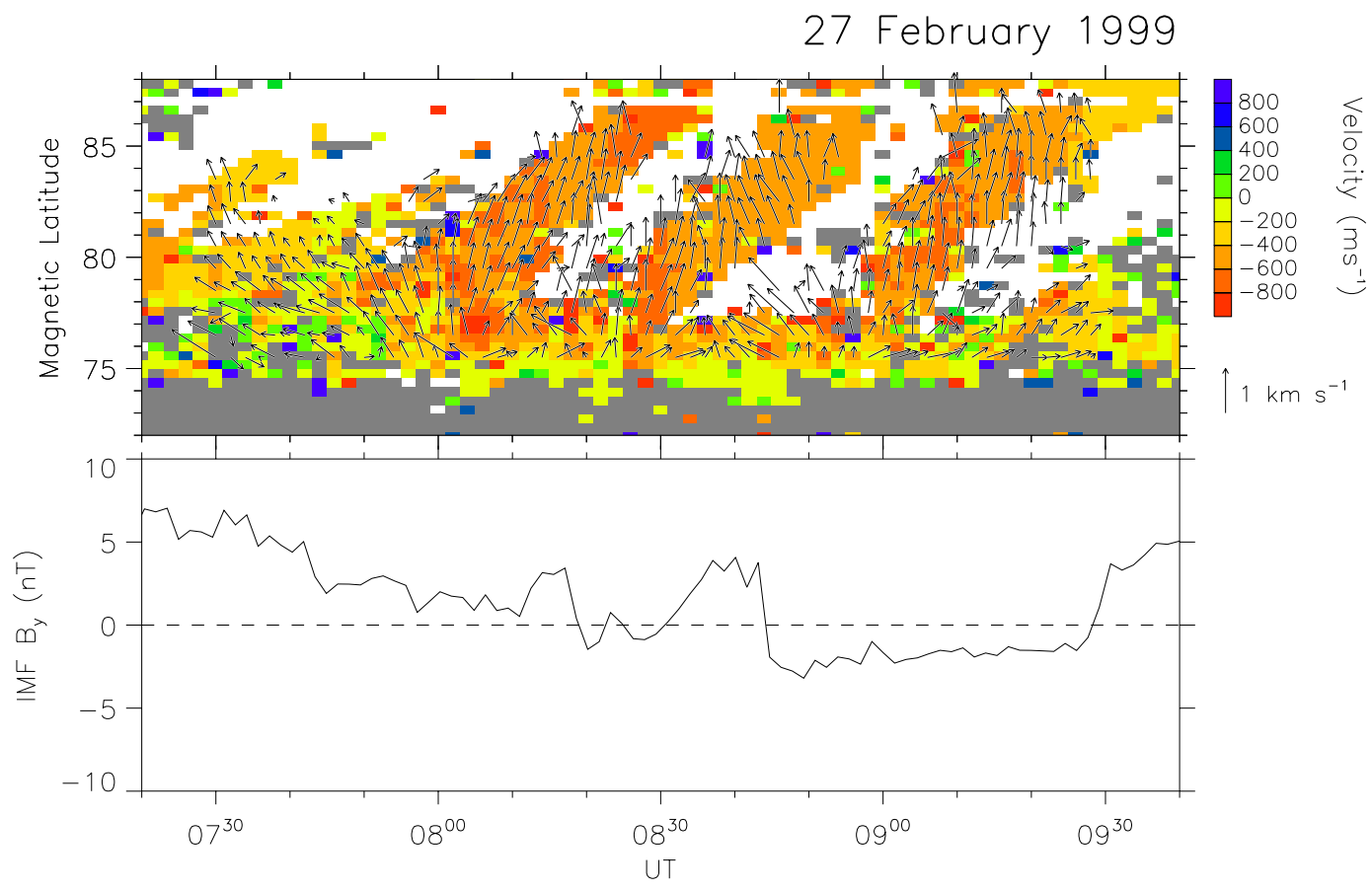

Fig. 3. An expanded view of the plasma drift latitude-time plot of Fig. 2, along with the $B_{Y}$ component of the IMF. Vectors calculated with a beam-swinging technique are superimposed on the plasma drift velocities. Vectors pointing towards the top and right of the panel indicate flow directed northwards and eastwards, respectively.

The next three panels of Fig. 2 illustrate the interplanetary magnetic field (IMF) orientation, in GSM coordinates, as measured by the Magnetic Fields Investigation (MFI) instrument on board the Wind spacecraft. The bottom two panels indicate that the solar wind speed and dynamic pressure, measured by the Solar Wind Experiment (SWE) instrument, remain relatively constant near $-300 \mathrm{~km} \mathrm{~s}^{-1}$ and $4 \mathrm{nPa}$, respectively, throughout this interval. At this time Wind is located downsteam of the Earth, though outside the magnetopause and magnetosheath, near $[X, Y, Z]=$ $\left[-47 R_{E},-49 R_{E},-4 R_{E}\right]$. Given the solar wind speed, the magnetospheric response to changes in the IMF are expected to be observed approximately $20 \mathrm{~min}$ before these features reach the Wind location; the IMF and solar wind time series in Fig. 2 have been shifted accordingly. This timing can be verified by comparing the radar observations of the auroral oval with the $B_{Z}$ component of the IMF. Prior to 07:40 UT the equatorward edge of the auroral oval is located near a latitude of $79^{\circ}$. Then, between 07:40 and 08:10 UT, this auroral boundary progresses equatorward, to near $75^{\circ}$ latitude. The start of this equatorward motion is found to correspond to a sharp southward turning of the IMF (indicated by vertical dot-dashed line). This can then be understood as the auroral response to a switch-on of reconnection at the dayside magnetopause and the resultant accumulation of new open flux in the polar cap. This correspondence between the IMF and auroral observations, and others that will be discussed below, give confidence in the assumed solar wind propagation delay.

Most interesting during this interval are the poleward- propagating backscatter features observed poleward of the auroral oval. Features of this nature have previously been identified as polar cap patches by Rodger et al. (1994). Several patches are observed through out the interval, but this study will concentrate on the three present between 07:50 and 09:40 UT, as these originate at relatively low-latitudes and hence remain within the field-of-view of the radar for the longest time. These patches have been given the identifying letters $\mathrm{A}$ to $\mathrm{C}$ to aid discussion. Each patch drifts polewards with a velocity of $500 \mathrm{~m} \mathrm{~s}^{-1}$, commensurate with the plasma drift velocity within the patches. This strongly suggests that each patch is drifting within the background convection flow. In the same manner to the patches observed by Rodger et al., the spectral widths within the patches start high after their inception, comparable with those of the cusp region, but decrease to low levels as the patches progress to higher latitudes. Interestingly, the backscatter power is greatest near the trailing edges of the patches. In Fig. 1, patch B is observed as the region of backscatter poleward of the auroral oval. The spatial extent of this patch is also typical of $\mathrm{A}$ and $\mathrm{C}$, being approximately $5^{\circ}(\approx 550 \mathrm{~km})$ in latitudinal width and $1000 \mathrm{~km}$ across.

Patches $\mathrm{A}, \mathrm{B}$, and $\mathrm{C}$ are formed during an interval when IMF $B_{Z}$ remains uniform near $-12 \mathrm{nT}$ for $50 \mathrm{~min}$. During this same interval there is a trend in IMF $B_{Y}$ from small and positive to small and negative. However, superimposed on this trend are a couple of excursions to positive and negative $B_{Y}$ (indicated by vertical dashed lines). We suggest that these variations in $B_{Y}$ are partially responsible for modulating the 


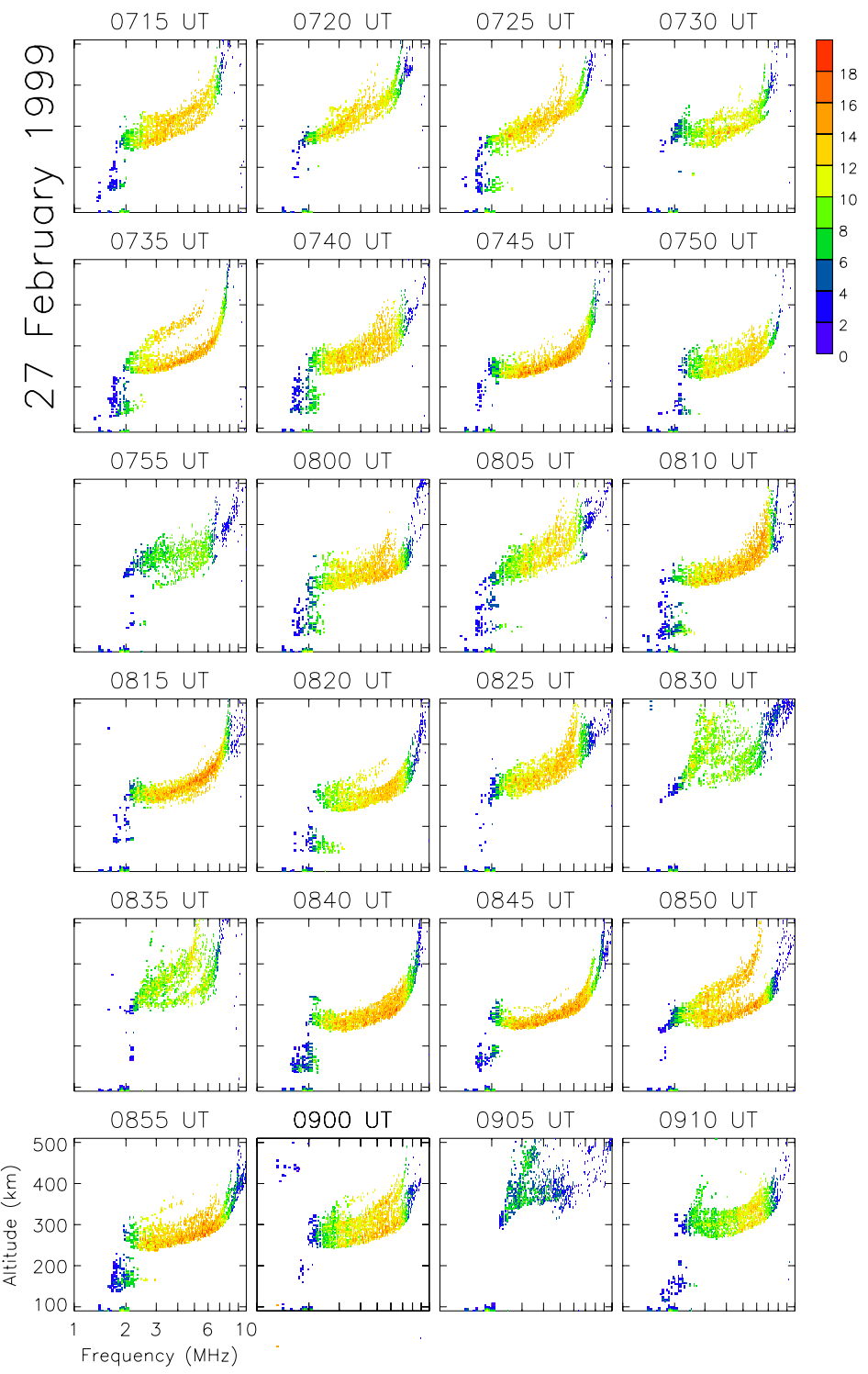

Fig. 4. A sequence of 24 ionograms from the Longyearbyen ionosonde, covering the interval over which polar patches $\mathrm{A}, \mathrm{B}$, and $\mathrm{C}$ were observed by the radar.

patch formation, in much the same way that was proposed by Rodger et al. (1994). This is supported by Fig. 3 which shows a close-up of the radar observations of the polar patches, with superimposed flow vectors determined by the beamswinging technique first introduced in Fig. 1b. Of greatest importance to the patch formation are the flows imaged in the $75^{\circ}-78^{\circ}$ latitudinal region, i.e. within the auroral oval. At the start of this interval, near 07:30 UT, the flows within this region are directed westwards and polewards. Such flow is consistent with the expected direction of plasma drift in the vicinity of the cusp region, on recently reconnected field lines acting under the magnetic tension force exerted by the IMF when the $B_{Y}$ component is positive. Poleward of this region the plasma drift becomes more directed towards the pole. As the time approaches 08:00 UT and $B_{Y}$ approaches $0 \mathrm{nT}$, the flow in the cusp region rotates towards the pole. At this time polar patch A begins to progress polewards; thereafter, the direction of plasma flow within the patch remains directed towards the pole for the duration of its life within the field-of-view of the radar. At approximately 08:10 UT, $B_{Y}$ steps to more positive values, and the flow within the cusp region becomes directed westward once again. This is accompanied by a detachment of the polar patch from the cusp backscatter. Shortly after, at 08:20UT, $B_{Y}$ steps abruptly to small and negative values and the flow within the cusp rotates to the north and slightly to the east. This poleward plasma drift once again leads to the poleward progression of backscatter, this time forming patch $\mathrm{B}$. In a similar manner to patch $\mathrm{A}$, this second detaches itself from the auroral oval when $B_{Y}$ turns positive and flow within the cusp region becomes significantly zonal, first eastward and then westward, after 08:30 UT. The formation of patch $\mathrm{C}$ follows very similar lines in that an abrupt negative turning of IMF $B_{Y}$ at 08:40 UT leads to a rotation of flow through north to east; when the flow is directed northward, backscatter is entrained within it and is carried into the polar cap. The detachment of 


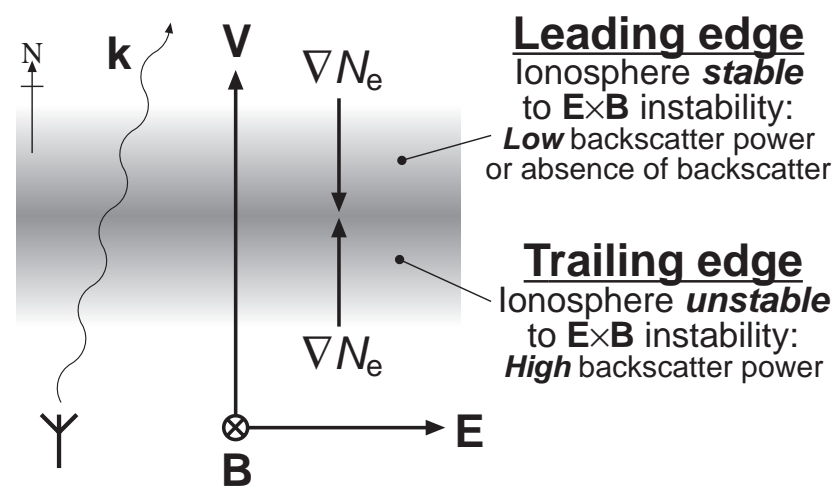

Fig. 5. A schematic diagram indicating the region of the polar patches most likely to give rise to ionospheric irregularities from which the radar can scatter. $\boldsymbol{B}$ is the terrestrial magnetic field, $\boldsymbol{E}$ the convection electric field, $\boldsymbol{V}$ the direction of plasma drift, and $\boldsymbol{k}$ the radar wave vector. $\nabla N_{e}$ indicates the direction of horizontal plasma density gradients at the leading and trailing edges of the polar patch. Irregularity generation occurs where $\boldsymbol{V}$ and $\nabla N_{e}$ have a parallel component, i.e. at the trailing edge of the patch.

this patch from the main oval has no obvious IMF precursor, but seems to occur when the cusp flow, under the influence of ongoing negative $B_{Y}$ conditions has rotated fully toward the east. Careful examination of the flows near the detachment of patch B suggests that there again, the backscatter appears to detach from the cusp as the cusp flow rotates away from poleward, towards the east, shortly before the negative excursion of $B_{Y}$ drives westward plasma drift, as will be discussed further below. In summary, the creation of each patch appears associated with a rotation of flow in the cusp region from westward, through northward, to eastward.

Now we turn to measurements made by the vertical ionospheric sounder located at Longyearbyen, at a magnetic latitude of $75^{\circ}$ (see Fig. 1). Examination of Figs. 1 and 2 indicates that this location corresponds to the equatorward edge of the cusp radar backscatter. In other words, the ionosonde is located very near to the region in which the patches are formed, and hence gives important information regarding this formation process. Figure 4 presents a sequence of ionograms from 07:15 to 09:10 UT, each separated by $5 \mathrm{~min}$. In general, the ionograms are well defined, indicating a maximum F-region plasma frequency, $f_{o} \mathrm{~F} 2$, between 7.5 and $10 \mathrm{MHz}$, and an F-region altitude near $250 \mathrm{~km}$. Exceptions to this rule occur at 07:55, 08:30-08:35, and 09:05 UT. At these times, the return power reduces significantly, the Fregion traces become much more spread, and the F-region altitude appears to increase to above $300 \mathrm{~km}$. We interpret this signature as a significant decrease in the F-region electron density above the ionosonde. Any returns observed at the higher frequencies then originate at locations away from zenith, reflected from horizontal gradients in the F-region electron density. These returns will have slant ranges greater than the height of the undisturbed F-region, and hence appear on the ionogram to be reflected from higher altitudes. There is evidence, certainly at 08:30 and 09:05 UT, that the peak plasma frequency above the ionosonde at these times is between 3 and $4 \mathrm{MHz}$, a drop in electron density by a factor of $\approx 5$ from the background F-region. These spread ionograms are in contrast to the coherent, well-defined offvertical traces seen at other times (the second, "higher altitude" trace in each case), for instance 07:35 and 08:50 UT, which probably indicates a large-scale gradient, located away from zenith, acting as a smooth reflector. Had the ionosonde sounded with higher time resolution it would have been possible to follow the range-variation of these off-vertical traces in order to determine the motion of the reflecting surfaces. As it is, we can conclude that: at times the electron density above the ionosonde is severely depleted and at these times very spread and weak ionograms are observed; as these depletions propagate away from the ionosonde, the large-scale electron density gradients associated with them act as reflectors which can give rise to off-vertical reflections, seen as a second F-region trace. The sequence of events described here is shown schematically in Fig. 11 (denoted "winter").

To find the relationship between the ionosonde measurements and the radar patches, we can extrapolate back the location of the trailing edge of each patch to find the time at which this crossed a latitude of $75^{\circ}$, the location of the ionosonde. Doing so indicates that the trailing edge of the patches in all three cases correlates very well with the times at which weak and spread ionograms - indicative of depleted F-region electron densities - were observed by the ionosonde. The gaps between the radar patches correspond, then, to electron density depletions. From this, the electron density structure within the patches can be predicted to be an equatorward-directed electron density gradient at the leading edge and a poleward-directed gradient at the trailing edge, as illustrated schematically in Fig. 5. This is consistent with the observed backscatter power enhancement at the trailing edge of the patches, as the ionosphere is unstable (stable) to the $\boldsymbol{E} \times \boldsymbol{B}$ (or gradient drift) instability when $\nabla N_{e}$ is parallel (anti-parallel) to the direction of plasma drift $\boldsymbol{V}$ (e.g. Cerisier et al., 1985). Backscatter is observed throughout the patches, but the irregularities appear with the greatest cross section at the trailing edges.

The question then remains as to what is the causative factor in producing these depletions in the F-region electron density. In the model of Rodger et al. (1994) these depletions are produced by narrow east-west aligned channels of enhanced flow - up to $3 \mathrm{~km} \mathrm{~s}^{-1}$ - in the cusp region. Such channels, known as flow channel events or FCEs, were first reported by Pinnock et al. (1993), and are thought to be associated with transient dayside reconnection. Rodger et al. (1994) hypothesised that the high electric field associated with FCEs produced elevated ion temperatures and hence a high ionospheric recombination rate, leading to electron density depletion. However, although zonal flow bursts are observed during the present interval, the flow speed associated with these channels reaches no higher than 1 to $1.5 \mathrm{~km} \mathrm{~s}^{-1}$. One such FCE is indicated in Fig. 1, in the backscatter associated with the auroral oval. In this, with a $1^{\circ}$ to $2^{\circ}$ width, the line-ofsight velocities vary relatively smoothly from approximately 


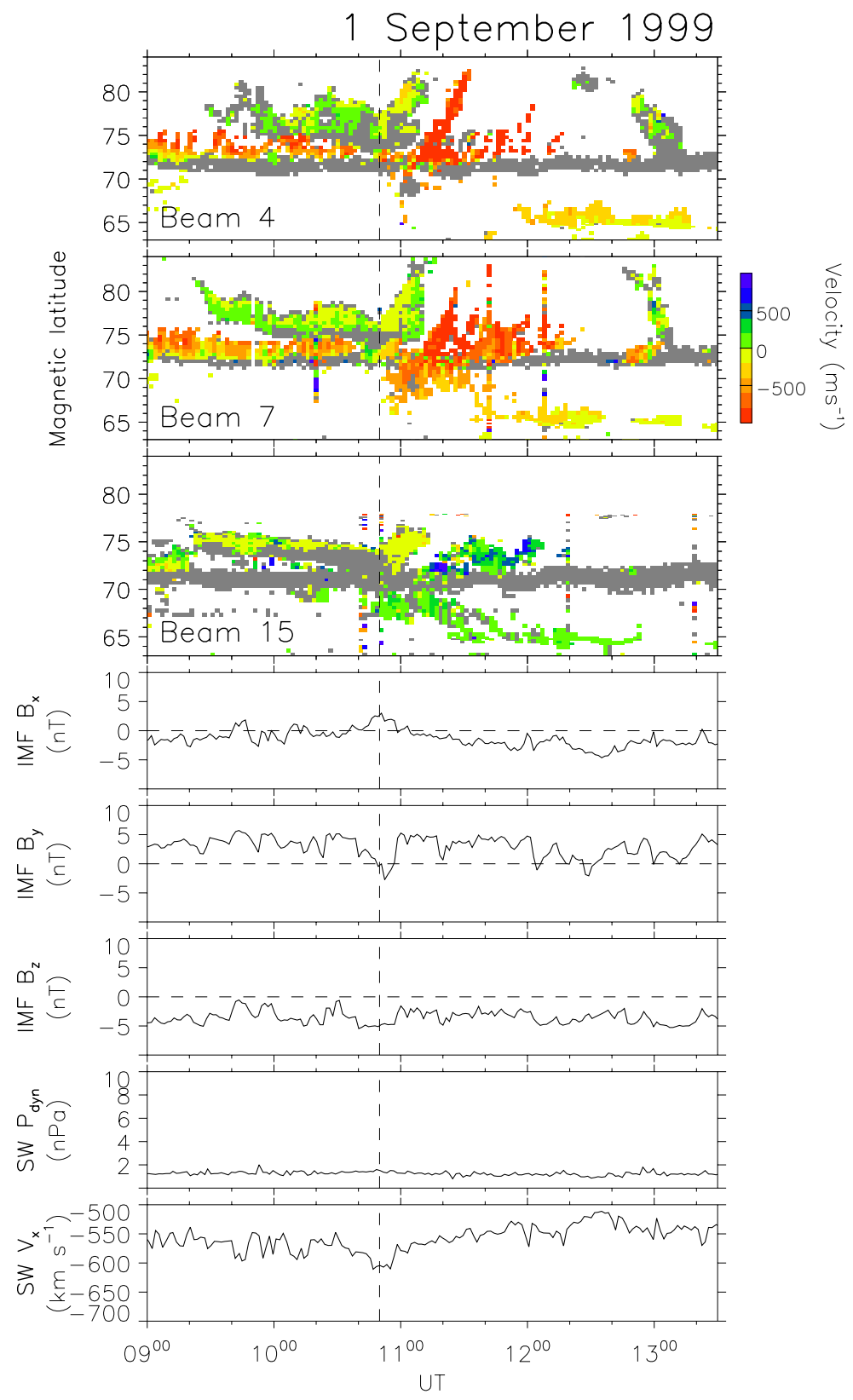

Fig. 6. Similar to Fig. 2, though for the 1 September 1999 interval. The top three panels indicate line-of-sight plasma drift from three different beam directions.
$500 \mathrm{~m} \mathrm{~s}^{-1}$ in the western-most beams to $-500 \mathrm{~m} \mathrm{~s}^{-1}$ towards the east. This indicates that the flow within this channel is predominantly zonal, with a velocity of approximately $1 \mathrm{~km} \mathrm{~s}^{-1}$. At this time polar patch $B$ has just detached from the auroral oval scatter, and the Longyearbyen ionosonde is observing a depleted F-region. The ion frictional heating associated with plasma drift of this velocity (corresponding to an electric field of $50 \mathrm{mV} \mathrm{m}^{-1}$ ) is not thought to be sufficient to produce a very significant electron density depletion. Modelling work by Schunk et al. (1975) suggests that electric fields of the order of $200 \mathrm{mV} \mathrm{m}^{-1}\left(4 \mathrm{~km} \mathrm{~s}^{-1}\right)$ are required to produce an F-region density depletion by a factor of 5 .

An alternative interpretation is that variations in the convection pattern, under the influence of the IMF, change the source of ionospheric plasma entering the polar cap through the cusp region, and hence modulate the polar cap F-region electron density. For instance, when flow through the cusp region is directed predominantly poleward, the ionospheric plasma entering the polar cap originates from sunlit subauroral latitudes. Figure 1a has superimposed upon it contours of solar zenith angle. At this time, Longyearbyen and the cusp region are located close to the solar terminator, at a solar zenith angle of $90^{\circ}$. For a short distance poleward of this, the ionosphere is still sunlit, but the undisturbed Fregion electron density falls off rapidly. This can be seen by examining ionograms from the Narssarssuaq ionosonde, which at this time is at a solar zenith angle of $102^{\circ}$ (see Fig. 1a). Between 07:00 and 10:00 UT, $f_{o} \mathrm{~F} 2$ at LYR and 


\section{September 1999}
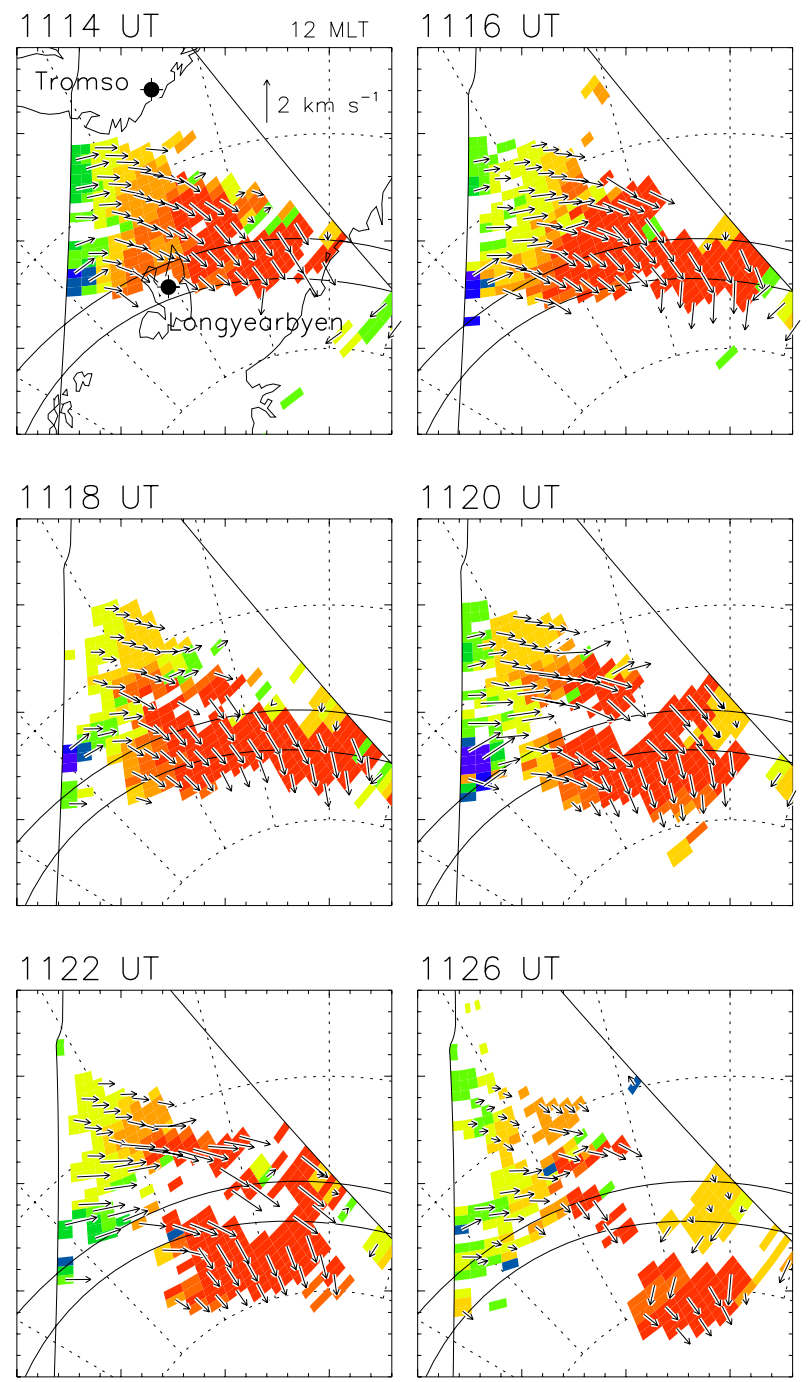

Fig. 7. A sequence of six radar scans, with superimposed beamswung vectors, showing the interval during which the 1 September 1999 polar patch was formed.

NSQ has values of approximately $8-10 \mathrm{MHz}$ and $3-4 \mathrm{MHz}$, respectively, a factor of 6 in electron density. An eastwardsdirected flow channel in the convection return flow region would take $\approx 15 \mathrm{~min}$ to convect low density plasma from the vicinity of NSQ into the high background plasma density regime near LYR. Equally, a westwards-directed flow channel would have the same effect, drawing low density plasma from the dawn sector into the cusp region. Thus, plasma transport could play a significant role in producing variations in F-region electron density above the Longyearbyen ionosonde. It is probable that both mechanisms, transport and plasma depletion in enhanced flow channels, leads to structuring of the ionospheric plasma entering the polar cap. These flow channels appear to be driven by the magnetic tension force exerted by the $B_{Y}$ component of the IMF, associated with asymmetry in the well-known twin-cell con- vection pattern, as suggested by Rodger et al. (1994).

\subsection{Interval 2}

We now turn our attention to a second interval, 09:00 to 13:30 UT, on 1 September 1999. During this interval the cusp is fully illuminated by the Sun, the zenith angle at Longyearbyen is close to $70^{\circ}$. This interval is displayed in Fig. 6, in the same format as Fig. 2 with one slight difference: the top three panels all display a line-of-sight velocity, but from three different beams, 4, 7, and 15. The CUTLASS observations will be described first.

A narrow region of ground backscatter is observed near $72^{\circ}$ latitude. This ground scatter is observed in the rearlobe of the radar antenna pattern (see Milan et al., 1997a), and is of little importance to the following discussion. Just poleward of this region, between approximately $73^{\circ}$ and $75^{\circ}$ latitude, is a region of ionospheric backscatter with large negative Doppler shifts, which we identify as the auroral oval. Interestingly, within this auroral scatter is evidence of quasi-periodic $(10 \mathrm{~min}$ ) small-scale poleward-moving features, especially during the intervals 09:00 to 09:40 UT and 11:20 to 12:00 UT in beam 4. These are the signatures of transient dayside reconnection, or flux transfer events (FTEs), as described by, for instance, Provan et al. (1998). These small-scale features stand in stark contrast to the largescale poleward-moving features observed between 10:55 and 11:35 UT, the polar patch which is the focus of this interval of study. While the FTEs propagate polewards, on average, by $3^{\circ}$ of latitude, this patch is observed to cover a latitudinal range of over $12^{\circ}$. As can be seen best in beam 7 , this first involves a significant equatorward step in the location of the auroral backscatter, from $72^{\circ}$ to $68^{\circ}$ latitude. This will be discussed in more detail below.

The last region of backscatter to be discussed is another region of ground backscatter, observed predominantly between 09:20 and 11:20 UT, and also after 12:40 UT, located at latitudes poleward of the auroral backscatter. The ACF analysis technique has not positively identified this region of backscatter as ground clutter, but we are confident in this interpretation due to the low Doppler velocity of the backscatter, and by comparison with the previous and following days of observation. Interestingly, at the time of the formation of the polar patch, this region of ground backscatter also moves poleward, disappearing at far ranges at 11:15 UT, and later reappearing at far ranges after 12:40 UT and progressing to nearer ranges.

Figure 7 presents six scans of the radar between 11:14 and 11:26 UT, around the time of the formation of the polar patch, projected onto magnetic latitude and MLT coordinates. Only ionospheric backscatter is shown and beam-swung vectors are superimposed. Prior to 10:50 UT, the only backscatter present is a band of auroral scatter near the location of the statistical oval superimposed on each panel. After this time, however, a region of backscatter formed at lower latitude the equatorward step in the auroral backscatter mentioned above - is seen in Fig. 7, just poleward of northern Scandi- 


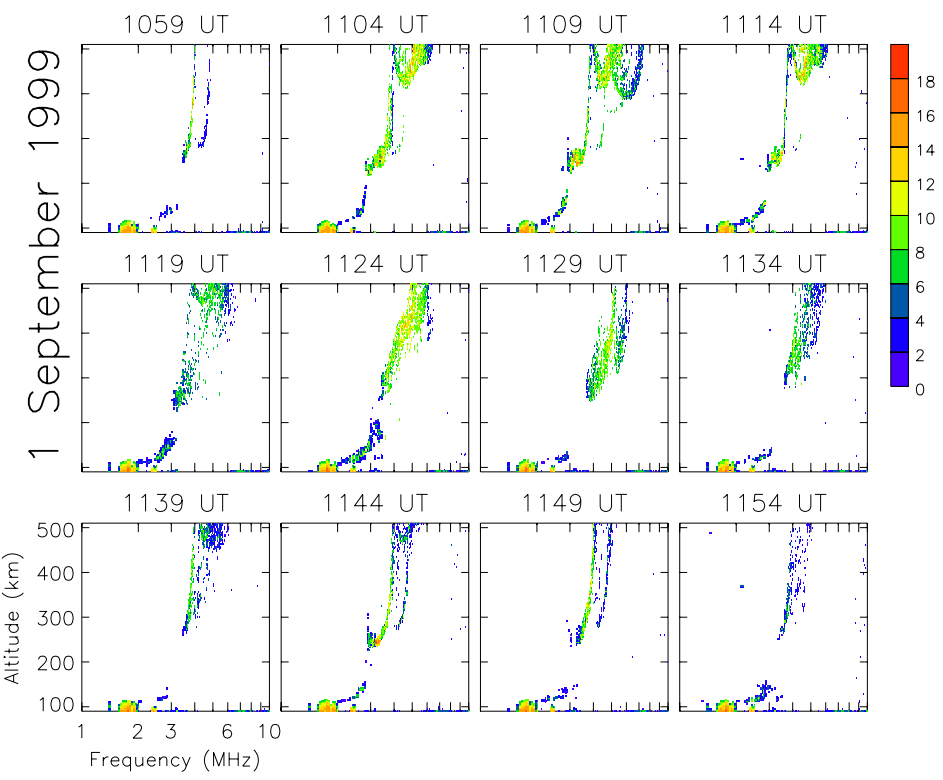

Fig. 8. A sequence of 12 ionograms from the Longyearbyen ionosonde, covering the interval over which the 1 September 1999 polar patch was observed by the radar. navia. Within this backscatter, at 11:14 UT, it is revealed that the convection pattern has extended to low-latitudes, allowing plasma from mid- or sub-auroral latitudes to gain entry into the polar cap through the cusp region. The convection velocity at this time is near $1 \mathrm{~km} \mathrm{~s}^{-1}$. Entrained within this flow, the poleward edge of the backscatter begins to progress to higher latitudes at this time. Between 11:18 and 11:22 UT, a higher velocity, $1.7 \mathrm{~km} \mathrm{~s}^{-1}$, channel of east-west zonal flow develops between $71^{\circ}$ and $73^{\circ}$ latitude, the plasma flow now mainly skirting around the oval. At this time, the plasma flowing at auroral latitudes originates at high-latitudes, and not at mid-latitudes as before. A separation becomes apparent between this flow channel and the backscatter poleward of it, and the polar patch becomes fully formed. Subsequently (11:26 UT and after), this patch drifts further into the polar cap.

The Longyearbyen ionosonde measurements from this time are shown in Fig. 8. At 10:59UT, the undisturbed ionosphere has $f_{o} \mathrm{~F} 2 \approx 4 \mathrm{MHz}$. Between 11:04 and 11:44 UT an extension of the F-region trace is observed, extending to $f_{o} \mathrm{~F} 2 \approx 6 \mathrm{MHz}$ (the trace at higher frequencies is presumed to be the $x$-mode component). At first (11:04 to 11:14 UT) this has the appearance of an extra ionospheric layer at very high altitudes. Over time, this becomes assimilated with the preexisting F-region trace, which itself now extends up to $6 \mathrm{MHz}$ (11:24 to 11:29 UT). Subsequently (11:34 to 11:44 UT), the F-region extension reappears. By 11:49UT, the ionosphere has returned to its original, undisturbed, state, with $f_{o} \mathrm{~F} 2 \approx 4$ $\mathrm{MHz}$. We interpret this sequence of ionograms as indicating that a region of high electron density appeared equatorward of the ionosonde near 11:00 UT, propagated poleward over the zenith of the ionosonde near 11:30 UT, thereafter continuing poleward until it was no longer observed after 11:50 UT. The sequence is shown schematically in Fig. 11 (denoted "summer"). We suggest that this region of enhanced plasma density originated at mid- or sub-auroral latitudes, was carried poleward by the enlarged convection pattern, and was then broken off by a flow channel containing low density plasma originating at higher latitudes. This model requires that the ionosphere in the vicinity of northern Scandinavia had $f_{o} \mathrm{~F} 2 \approx 6 \mathrm{MHz}$ at the start of the interval. Indeed, this is the case as the ionosonde located at Troms $\emptyset$ measured $f_{o} \mathrm{~F} 2$ $=6.8 \mathrm{MHz}$ at 10:36 UT. Interestingly, a decrease in $f_{o} \mathrm{~F} 2$ was thereafter observed, reaching a value of $5.4 \mathrm{MHz}$ (a decrease to $60 \%$ of the original electron density) at $11: 36 \mathrm{UT}$. The ionosphere did not recover back to $6.8 \mathrm{MHz}$ until 12:48 UT. This is consistent with the proposed model, as the high density plasma convected polewards from Troms $\emptyset$ to form the polar patch must be replaced by low density plasma from the nightside ionosphere entrained within the convection return flow. The mid-latitude electron density then returns to its undisturbed level through solar insolation. Finally, this decrease in $f_{o} \mathrm{~F} 2$ at Troms $\varnothing$ between 10:40 and 12:50 UT is consistent with the radar observations of ground backscatter at far ranges. The propagation mode by which this ground clutter is observed has a path midpoint near Troms $\emptyset$. As $f_{o} \mathrm{~F} 2$ decreases, the propagation "skip distance", the nearest range to which radar energy is refracted to the ground, increases and the backscatter moves to further ranges. As $f_{o} \mathrm{~F} 2$ recovers, the skip distance decreases again and the ground clutter returns to its original location. This is exactly the behaviour observed in Fig. 6.

The bottom panels of Fig. 6 show the simultaneous solar wind and IMF measurements made at the Wind spacecraft $\left([X, Y, Z]=\left[80 R_{E}, 19 R_{E},-10 R_{E}\right]\right)$, time-shifted by a solar wind propagation delay of $15 \mathrm{~min}$. Throughout the interval the solar wind dynamic pressure and solar wind velocity are approximately constant. Also, little variation is observed in IMF $B_{Z}$, which takes values between -1 and $-5 \mathrm{nT}$ during the interval. The most significant upstream 


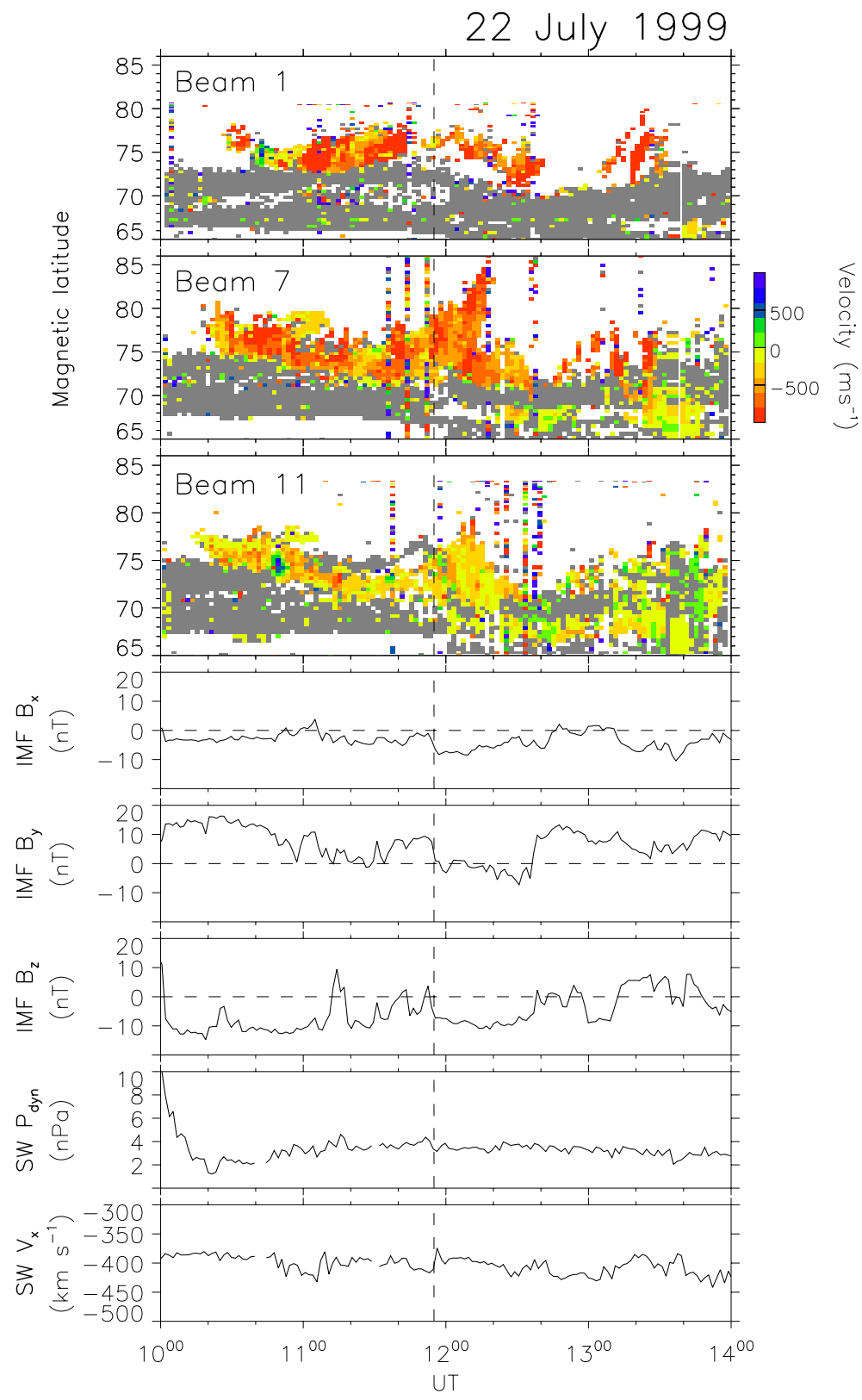

Fig. 9. Similar to Fig. 6, though for the 22 July 1999 interval.

precursor of the polar patch formation appears to be a switch in IMF $B_{Y}$ from $5 \mathrm{nT}$ to $-2 \mathrm{nT}$ and back to $5 \mathrm{nT}$, observed between 10:40 and 11:00 UT. It is apparently this variation in $B_{Y}$ which produces the change in the convection pattern that draws mid-latitude plasma into the polar cap. It is not clear what drives the flow channel that separates the polar patch from the auroral scatter, though this could be a signature of transient reconnection, as suggested by Rodger et al. (1994).

\subsection{Interval 3}

We now very briefly describe a final interval of interest, on 22 July 1999, illustrated in Fig. 9 in the same format as Fig. 6. This interval is very similar to that described above from 1 September 1999, and illustrates the reproducibility of this po- lar patch formation mechanism. At approximately 12:00 UT, a polar patch is seen to propagate towards the pole, away from scatter associated with the auroral oval. The formation of this patch occurs simultaneously with a significant change in the orientation of the IMF, a change in both the $B_{Y}$ and $B_{Z}$ components. Figure 10 shows a sequence of six scans from 11:52 to $12: 12$ UT. At the start of the interval, flow within the cusp region is directed polewards, and backscatter entrained within the flow is convected into the polar cap. After 12:06 UT, a significant east-west zonal component to the flow develops in the auroral zone, though at no time does the flow speed exceed $1 \mathrm{~km} \mathrm{~s}^{-1}$, and at 12:12 UT, the polar patch is seen to begin separating from the auroral scatter. This patch formation is accompanied by enhanced $f_{o} \mathrm{~F} 2$ observed by the Longyearbyen ionosonde, especially between 12:00 
and 12:10 UT. Again, during this interval, the polar patch formation mechanism appears to be as follows: when flow is directed polewards through the cusp region, high density plasma from mid-latitudes enters the polar cap; when a zonal component to the plasma flow develops in the auroral zone, in response to changes in the IMF, the low density plasma from a source near the solar terminator is convected into the polar cap and the polar patch becomes separated from the auroral scatter.

\section{Summary and conclusion}

Three intervals of polar patch formation have been presented. In all three intervals, the mechanism leading to a structured F-region plasma density in the polar cap appears the same. Following a change in the orientation of the IMF, usually in the $B_{Y}$ component, the source of the plasma entering the convection throat changes. When the plasma drift through the cusp region is predominantly directed polewards, high electron density plasma from mid- or sub-auroral latitudes is convected into the polar cap. If the plasma drift in the cusp region becomes more zonal, low density plasma entrained in the convection return flow then enters the polar cap. Such switching between plasma source regions produces the structuring of the F-region plasma associated with polar cap patches. This structuring introduces significant horizontal electron density gradients into the ionosphere, within which ionospheric irregularities develop through the action of the gradient drift instability. It is these irregularities which are then visible in HF radar observations as they provide the targets from which such radars coherently scatter.

In winter months, the ambient electron density equatorward of the cusp region is relatively high, and the structuring is primarily achieved by introducing depleted plasma from the convection return flow. It is also possible that in situ depletion by high electric fields associated with flow channel events is also significant, as suggested by Rodger et al. (1994), but the drift velocities observed in the present case are relatively low. In summer months, the ambient plasma density in the cusp region is lower, and the structuring is achieved by drawing enhanced plasma densities from midlatitudes into the polar cap. In other words, in summer, polar patches are enhancements of the polar cap tongue of ionisation, whereas in winter, they are produced by depletions of the tongue of ionisation. These different mechanisms are shown schematically in Fig. 11, along with the ionogram traces expected, for comparison with Figs. 4 and 8.

This mechanism can lead to significant structuring of the dayside sub-auroral latitude electron density. In the second example shown, on 1 September 1999, the high electron density plasma from the sub-auroral region that was drawn into the cusp region to produce the polar patch was replaced by low density plasma from the convection return flow. The time-scales for solar production of F-region ionisation are sufficiently long so that plasma depletion can persist for long periods. It is possible to think of this plasma depletion as

\section{July 1999}
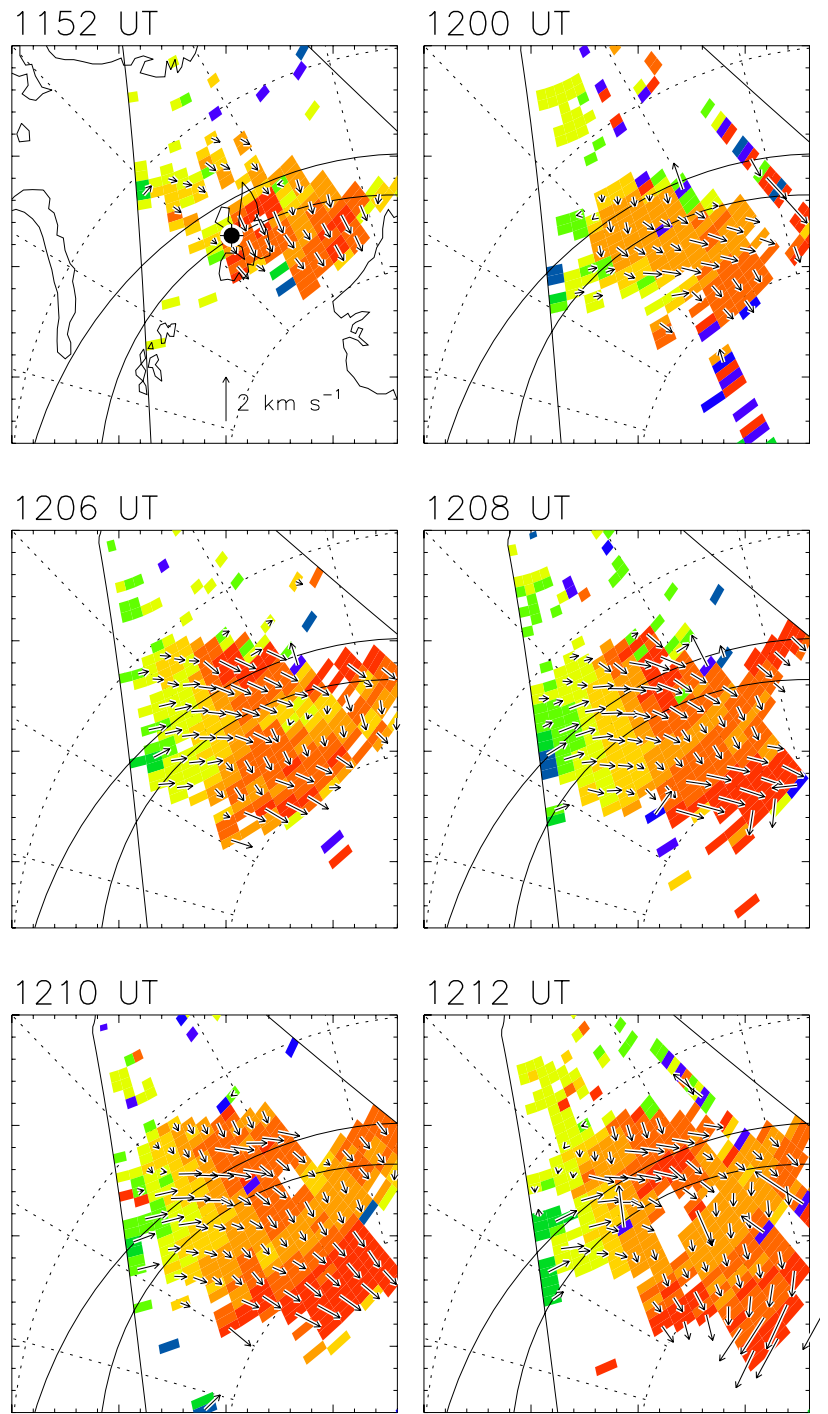

Fig. 10. Similar to Fig. 7 for the 22 July 1999 interval.

constituting an enlarged mid-latitude trough, extending from the dusk sector into the noon sector ionosphere, as predicted by Watkins (1978). In addition, the two examples presented from summer months argue against in situ production of enhanced plasma densities in the cusp region through precipitation. The Longyearbyen ionosonde, located at cusp latitudes, observes patches drifting towards the ionosonde from mid-latitudes, before appearing above the ionosonde zenith, and subsequently drifting away polewards.

It is possible that structuring of the electron density in the convection throat region occurs on a variety of spatial scale sizes and through a variety of mechanisms. Once such gradients are formed they can persist for several tens of minutes while entrained within the background convection pattern. As discussed above, these gradients then generate irregularities which provide targets for HF radars, hence acting as tracers of the convection flow: not only do the backscatter 


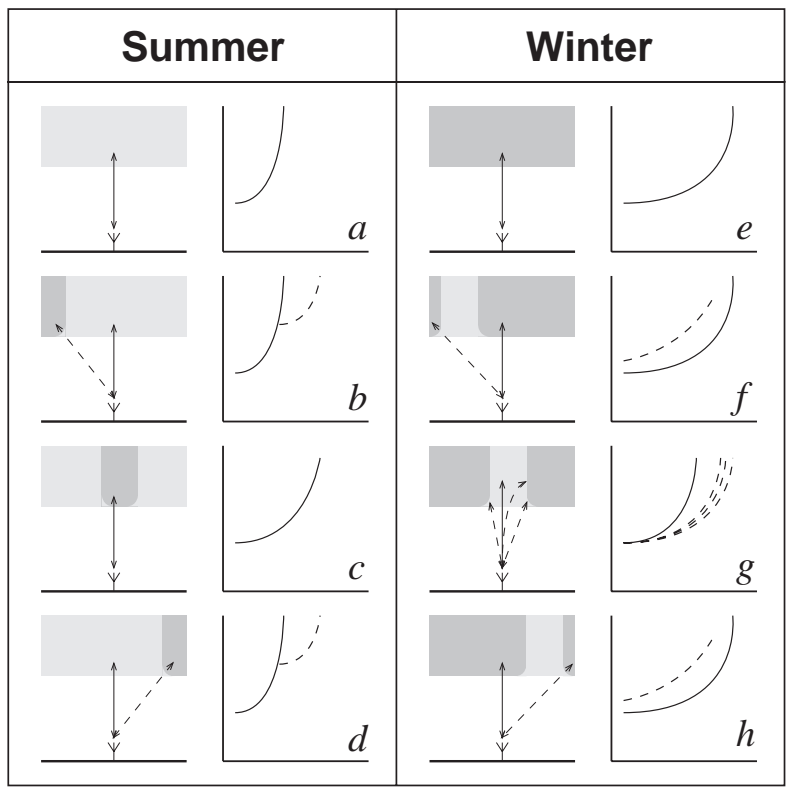

Fig. 11. A schematic figure showing the relationship of the polar patch to the ambient "tongue of ionisation" in summer months and winter months. For summer and winter a sequence of diagram is shown, each a cut along the south-north (left-right) meridian, with the ionosonde shown at the bottom. Higher and lower electron densities are indicated by darker and lighter shaded regions. The reflected ionosonde signals are shown by arrows, solid arrows indicating reflection above, and dashed arrows off-zenith returns. To the right of each diagram is the ionogram expected from the indicated radio propagation, solid and dashed traces corresponding to overhead and off-zenith returns. In summer, the tongue of ionisation is of relatively low density and polar patches are occasional enhancements above this background level. In winter, the tongue of ionisation is of high density, and patches are defined by short depletions in this electron density.

features move with the flow, but also the Doppler shift of echoes within the features should be consistent with the lineof-sight component of the flow velocity. The plasma density gradients are generated by transient processes occurring near the cusp, and so their discrete nature (and hence the discrete nature of the backscatter patches) is a "fossil" describing the past history of events occurring in the dayside convection pattern. In this study we have concentrated on large-scale features which seem to be created by changes in the convection pattern associated with IMF variations. On smaller scales, however, other processes such as transient reconnection may also structure the ionospheric plasma density giving rise to discrete radar targets, as described by Rodger et al. (1994). This then may also be the generating mechanism for poleward-moving radar auroral forms observed in association with flux transfer events (e.g. Provan et al., 1998; Milan et al., 2000), such as those which are present in our second example, 1 September 1999 (Fig. 6). The difference in the life time of large- and small-scale features may be dependent on the depth of density troughs (or conversely, the magnitude of density peaks) produced by the structuring process and consequently the time taken for the gradients to decay through diffusion or insolation. We note that as the ionospheric structuring within large-scale polar patches appears different between summer and winter conditions, this may also have repercussions for the observation of smaller scale features.

Acknowledgements. CUTLASS is supported by the Particle Physics and Astronomy Research Council (PPARC grant no. PPA/R/R/1997/00256), UK, the Swedish Institute for Space Physics, Uppsala, and the Finnish Meteorological Institute, Helsinki. The authors thank the principle investigators, R. P. Lepping and K. Ogilvie, for the use of key parameters from the Wind MFI and SWE instruments, respectively. SEM was supported on PPARC grant no. PPA/G/O/1999/00181.

The Editor in chief thanks J. Sojka and S. Basu for their help in evaluating this paper.

\section{References}

Anderson, D. N., Buchau, J., and Heelis, R. A.: Origin of density enhancements in the winter polar cap ionosphere, Radio Sci., 23, 513, 1988.

Baker, K. B., Greenwald, R. A., Ruoheniemi, J. M., Dudeney, J. R., Pinnock, M., Newell, P. T., Greenspan, M. E., and Meng, C.I.: Simultaneous HF radar and DMSP observations of the cusp, Geophys. Res. Lett., 17, 1869, 1990.

Baker, K. B., Dudeney, J. R., Greenwald, R. A., Pinnock, M., Newell, P. T., Rodger, A. S., Mattin, N., and Meng, C.-I.: HF radar signatures of the cusp and low-latitude boundary layer, J. Geophys. Res., 100, 7671, 1995.

Buchau, J., Reinisch, B. W., Weber, E. J., and Moore, J. G.: Structure and dynamics of the winter polar cap F-region, Radio Sci., 18, 995, 1983.

Cerisier, J. C., Berthelier, J. J., and Beghin, C.: Unstable density gradients in the high-latitude ionosphere, Radio Sci., 20, 755, 1985.

Crowley, G.: Critical review of ionospheric patches and blobs, URSI Review of Radio Science 1993-1996, (Ed) Stone, W. R., Oxford University Press, 619, 1996.

Decker, D. T., Valladares, C. E., Sheehan, R., Basu, S., Anderson, D. N., and Heelis, R. A.: Modelling daytime F-layer patches over Sondrestrom, Radio Sci., 29, 249, 1994.

Greenwald, R. A., Baker, K. B., Dudeney, J. R., Pinnock, M., Jones, T. B., Thomas, E. C., Villain, J.-P., Cerisier, J.-C., Senior, C., Hanuise, C., Hunsucker, R. D., Sofko, G., Koehler, J., Nielsen, E., Pellinen, R., Walker, A. D. M., Sato, N., and Yamagishi, H.: DARN/SuperDARN: A global view of the dynamics of highlatitude convection, Space Sci. Rev., 71, 761, 1995.

Knudsen, W. C.: Magnetospheric convection and the high latitude F2 ionosphere, J. Geophys. Res., 79, 1046, 1974.

Lockwood, M., and Carlson, H. C.: Production of polar cap electron density patches by transient magnetopause reconnection, Geophys. Res. Lett., 19, 1731, 1992.

Milan, S. E., Jones, T. B., Robinson, T. R., Thomas, E. C., and Yeoman, T. K.: Interferometric evidence for the observation of ground backscatter originating behind the CUTLASS coherent HF radars, Ann. Geophysicae, 15, 29, 1997a.

Milan, S. E., Yeoman, T. K., Lester, M., Thomas, E. C., and Jones, T. B.: Initial backscatter occurrence statistics from the CUTLASS HF radars, Ann. Geophysicae, 15, 703, 1997 b. 
Milan, S. E., Yeoman, T. K., and Lester, M.: The dayside auroral zone as a hard target for coherent HF radars, Geophys. Res. Lett., 25, 3717, 1998.

Milan, S. E., Lester, M., Cowley, S. W. H., Moen, J., Sandholt, P. E., and Owen, C. J.: Meridian-scanning photometer, coherent HF radar, and magnetometer observations of the cusp: a case study, Ann. Geophysicae, 17, 159, 1999a.

Milan, S. E., Yeoman, T. K., Lester, M., Moen, J., and Sandholt, P. E.: Post-noon two-minute period pulsating aurora and their relationship to the dayside convection pattern, Ann. Geophysicae, $17,877,1999 b$

Milan, S. E., Lester, M., Cowley, S. W. H., and Brittnacher, M.: Convection and auroral response to a southward turning of the IMF: Polar UVI, CUTLASS and IMAGE signatures of transient magnetic flux transfer at the magnetopause, J. Geophys. Res., 105, $15741,2000$.

Ogawa, T., Nishitani, N., Pinnock, M., Sato, N., Yamagishi, H., and Yukimatu, A. S.: Antarctic HF radar observations of irregularities associated with polar patches and auroral blobs: A case study, J. Geophys. Res., 103, 26 547, 1998.

Pinnock, M., Rodger, A. S., Dudeney, J. R., Baker, K. B., Newell, P. T., Greenwald, R. A., and Greenspan, M. E.: Observations of an enhanced convection channel in the cusp ionosphere, J. Geophys. Res., 98, 3767, 1993.

Provan, G., Yeoman, T. K., and Milan, S. E.: CUTLASS Finland radar observations of the ionospheric signatures of flux transfer events and the resulting plasma flows, Ann. Geophysicae, 16 , $1411,1998$.

Rodger, A. S., Pinnock, M., Dudeney, J. R., Baker, K. B., and Greenwald, R. A.: A new mechanism for polar patch formation,
J. Geophys. Res., 99, 6425, 1994.

Rodger, A. S., Mende, S. B., Rosenberg, T. J., and Baker, K. B.: Simultaneous optical and HF radar observations of the ionospheric cusp, Geophys. Res. Lett., 22, 2045, 1995.

Rodger, A. S. and Graham, A. C.: Diurnal and seasonal occurrence of polar patches, Ann. Geophysicae, 14, 533, 1996.

Rodger, A. S. and Rosenberg, T. J.: Riometer and HF radar signatures of polar patches, Radio Sci., 34, 501, 1999.

Ruohoniemi, J. M., Greenwald, R. A., Baker, K. B., Villain, J.-P., Hanuise, C., and Kelley, J. D.: Mapping high latitude plasma convection with coherent HF radars, J. Geophys. Res., 94, 13 463, 1989.

Schunck, R. W., Raitt, W. J., and Banks, P. M.: Effect of electric fields on the daytime high-latitude E- and F-regions, J. Geophys Res., 80, 3121, 1975.

Sojka, J. J., Bowline, M. D., Schunck, R. W., Decker, D. T., Valladares, C. E., Sheehan, R., Anderson, D. N., and Heelis, R. A.: Modelling polar cap F-region patches using time varying convection, Geophys. Res. Lett., 20, 1783, 1993.

Valladares, C. E., Basu, S., Buchau, J., and Friis-Christensen, E.: Experimental evidence for the formation and entry of patches into the polar cap, Radio Sci., 29, 167, 1994.

Walker, I. K., Moen, J., Kersley, L., and Lorentzen, D. A.: On the possible role of cusp/cleft precipitation in the formation of polar patches, Ann. Geophysicae, 17, 1298, 1999.

Watkins, B. J.: A numerical computer investigation of the polar Fregion ionosphere, Planet. Space Phys., 26, 559, 1978.

Weber, E. J., Buchau, J., Moore, J. G., Sharber, J. R., Livingstone, R. C., Winningham, J. D., and Reinisch, B. W.: F-layer ionization patches in the polar cap, J. Geophys. Res., 89, 1683, 1984. 